(c) American Dairy Science Association, 2004.

\title{
Multivariate Threshold Model Analysis of Clinical Mastitis in Multiparous Norwegian Dairy Cattle
}

\author{
B. Heringstad, ${ }^{1}$ Y. M. Chang, ${ }^{2}$ D. Gianola, ${ }^{1,2}$ and G. Klemetsdal ${ }^{1}$ \\ ${ }^{1}$ Department of Animal and Aquacultural Sciences, \\ Agricultural University of Norway, P. O. Box 5025, N-1432 Ås, Norway \\ ${ }^{2}$ Department of Dairy Science, \\ University of Wisconsin, Madison 53706
}

\begin{abstract}
A Bayesian multivariate threshold model was fitted to clinical mastitis (CM) records from 372,227 daughters of 2411 Norwegian Dairy Cattle (NRF) sires. All cases of veterinary-treated CM occurring from $30 \mathrm{~d}$ before first calving to culling or $300 \mathrm{~d}$ after third calving were included. Lactations were divided into 4 intervals: -30 to $0 \mathrm{~d}, 1$ to $30 \mathrm{~d}, 31$ to $120 \mathrm{~d}$, and 121 to $300 \mathrm{~d}$ after calving. Within each interval, absence or presence of CM was scored as "0" or " 1 " based on the CM episodes. A 12 -variate (3 lactations $\times 4$ intervals) threshold model was used, assuming that CM was a different trait in each interval. Residuals were assumed correlated within lactation but independent between lactations. The model for liability to CM had interval-specific effects of month-year of calving, age at calving (first lactation), or calving interval (second and third lactations), herd-5-yr-period, sire of the cow, plus a residual. Posterior mean of heritability of liability to $\mathrm{CM}$ was 0.09 and 0.05 in the first and last intervals, respectively, and between 0.06 and 0.07 for other intervals. Posterior means of genetic correlations of liability to $\mathrm{CM}$ between intervals ranged from 0.24 (between intervals 1 and 12) to 0.73 (between intervals 1 and 2), suggesting intervalspecific genetic control of resistance to mastitis. Residual correlations ranged from 0.08 to 0.17 for adjacent intervals, and between -0.01 and 0.03 for nonadjacent intervals. Trends of mean sire posterior means by birth year of daughters were used to assess genetic change. The 12 traits showed similar trends, with little or no genetic change from 1976 to 1986 , and genetic improvement in resistance to mastitis thereafter. Annual genetic change was larger for intervals in first lactation when compared with second or third lactation. Within lactation, genetic change was larger for intervals early in lactation, and more so in the first lactation. This
\end{abstract}

Received March 18, 2004.

Accepted April 21, 2004.

Corresponding author: B. Heringstad; e-mail: bjorg.heringstad@ iha.nlh.no. reflects that selection against mastitis in NRF has emphasized mainly CM in early first lactation, with favorable correlated selection responses in second and third lactations suggested.

(Key words: Bayesian method, clinical mastitis, genetic evaluation, multivariate threshold model)

Abbreviation key: $\mathbf{C M}=$ clinical mastitis, $\mathbf{N R F}=$ Norwegian Dairy Cattle.

\section{INTRODUCTION}

Most genetic studies of mastitis have been conducted with records from primiparous cows, and genetic evaluation of clinical mastitis $(\mathbf{C M})$ in Norway has been based primarily on first-lactation data (Heringstad et al., 2000). Few estimates of genetic correlations between susceptibility to mastitis in different lactations have been reported. Pösö and Mäntysaari (1996) used data from the first 3 lactations of Finnish Ayrshire cows and found estimates of genetic correlations ranging between 0.67 and 0.90 . Nielsen et al. (1997) reported genetic correlations ranging from 0.65 to 1.00 between mastitis in first, second, and third lactations, for Red Danish, Danish Friesian, and Danish Jersey cows. These studies used Gaussian linear sire models for parameter estimation. Because mastitis frequency is higher in later lactations, it is of interest to study whether the trait can be considered to be the same in first and later lactations.

Chang et al. (2001, 2002) estimated genetic correlations between CM in eleven 30-d intervals of first lactation Norwegian Dairy Cattle (NRF) using a multivariate threshold model. The posterior means of these genetic correlations ranged between 0.13 and 0.55 . Genetic correlations much lower than one suggest strongly that mastitis cannot be regarded as the same trait throughout lactation. However, their study was based on only 245 sires, so the genetic correlations could not be estimated precisely. Therefore, it is pertinent to re-estimate these correlations using a larger data set, as well as to expand the scope of the study to include later lactations. 
Our objectives were to infer heritability and genetic correlations involving $\mathrm{CM}$ in different intervals of the first 3 lactations of NRF cows, to compare sire evaluations from these intervals, and to estimate genetic change for $\mathrm{CM}$ in the first 3 lactations. A Bayesian multivariate probit threshold model was developed and fitted for this purpose.

\section{MATERIALS AND METHODS}

\section{Data}

Records were from a research database containing all phenotypic information from the Norwegian Dairy Herd Recording System from 1978 onward. Mastitis records from the first 3 lactations of daughters of 2411 NRF sires, progeny tested from 1978 through 1998, were included. The total dataset had 1.6 million cows represented. Records of daughters of AI sires with second batch daughters only (i.e., bulls progeny tested earlier than 1978 and foreign-proven bulls) and records of bulls with fewer than 20 daughters were excluded. Only first-crop daughters-i.e., when the difference between the birth year of a daughter and the birth year of sire was smaller than $6 \mathrm{yr}$-were included.

Average herd size is small in Norway, so to alleviate the well-known "extreme category problem" of the threshold model, herd years were grouped into herd-5yr effects. The data were restricted to include only cows first calving in a herd-5-yr class with at least 10 firstlactation cows. The edited dataset had 372,227 firstlactation cows, of which 247,692 had a second lactation and 147,051 had a third lactation. A total of 25,033 herd-5-yr classes were represented in the data. The sire pedigree file had 2726 males, including the 2411 sires with daughters in the dataset.

For each cow, all cases of veterinary-treated CM in the first 3 lactations, from $30 \mathrm{~d}$ before first calving to culling, $300 \mathrm{~d}$ after third calving, or fourth calving, whichever occurred first, were included. Each lactation was divided into 4 intervals: from $30 \mathrm{~d}$ before calving to calving, the first $30 \mathrm{~d}$ of lactation, from d 31 to 120 , and from d 121 to 300 . Within each of these intervals, absence or presence of mastitis was scored as "0" or " 1 ," respectively, based on whether the cow had at least one veterinary treatment of $\mathrm{CM}$ recorded in the interval. Culled cows were scored also in the interval in which they were culled, irrespectively of the number of days represented in the last interval. The overall mastitis frequencies in the total dataset were 20.6, 25.9, and $30.6 \%$ in the first, second, and third lactations, respectively, increasing from 1978 to 1995, and decreasing thereafter, as shown in Figure 1. Mastitis frequencies for each lactation interval ranged between 3.3 and $13.0 \%$, as given in Table 1 . About 33.5 and $60.5 \%$ of

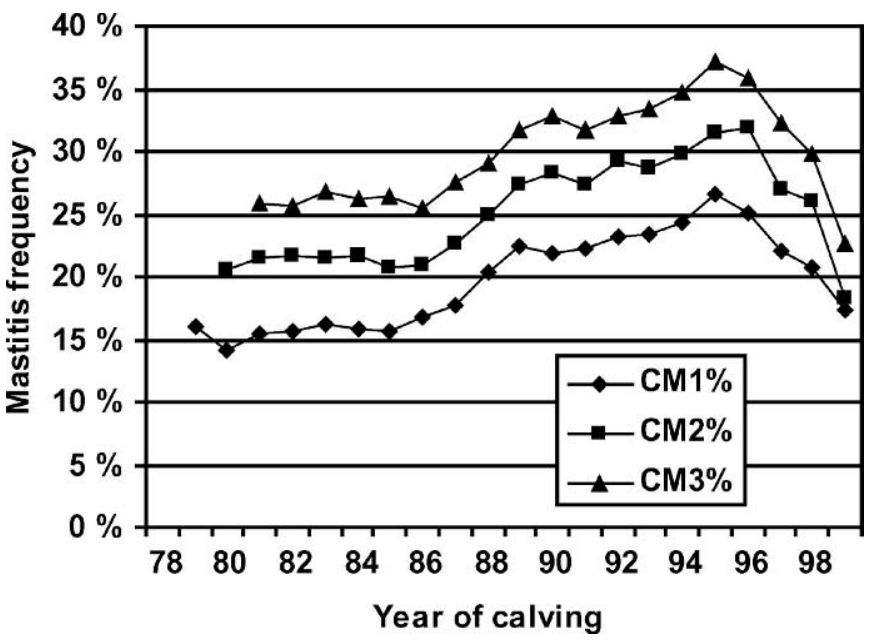

Figure 1. Frequency of clinical mastitis (CM) by year of calving: Percentage of cows that had at least one case of CM from $30 \mathrm{~d}$ prior to calving to $300 \mathrm{~d}$ after calving, culling, or next calving, whichever occurred first, for the first 3 lactations.

the cows were culled after 1 and 2 lactations, respectively, and the cumulative culling rate is shown in Table 1 .

\section{Statistical Model}

A 12-variate threshold-liability model was used, assuming that $\mathrm{CM}$ in each interval was a different trait. The application of univariate and multivariate threshold models in animal breeding goes back to Gianola and Foulley (1983), Foulley and Gianola (1984, 1986), Hoeschele et al. (1986), and Foulley et al. (1987), where approximate methods of analysis are described. However, recent advances in Markov chain Monte Carlo

Table 1. Mastitis frequency and cumulative culling rate in the 12 intervals of the first 3 lactations.

\begin{tabular}{lllll}
\hline Interval & Lactation & $\begin{array}{l}\text { Days from } \\
\text { calving }\end{array}$ & $\begin{array}{l}\text { Mastitis } \\
\text { frequency }{ }^{1}, \%\end{array}$ & $\begin{array}{l}\text { Cumulative } \\
\text { culling } \\
\text { rate }^{2}, \%\end{array}$ \\
\hline 1 & 1 & -30 to 0 & 3.9 & \\
2 & 1 to 30 & 8.8 & 0 \\
3 & 31 to 120 & 5.0 & 3.6 \\
4 & & 121 to 300 & 7.0 & 10.3 \\
5 & 2 & -30 to 0 & 3.3 & \\
6 & & 1 to 30 & 9.9 & 33.5 \\
7 & 31 to 120 & 9.3 & 35.2 \\
8 & 121 to 300 & 9.8 & 40.6 \\
9 & 3 & -30 to 0 & 3.8 & \\
10 & & 1 to 30 & 13.0 & 60.5 \\
11 & & 31 to 120 & 11.2 & 61.9 \\
12 & 121 to 300 & 11.1 & 65.6 \\
\hline
\end{tabular}

${ }^{1}$ Percentage of cows with at least one case of clinical mastitis during the interval.

${ }^{2}$ Percentage of cows that were culled before the start of the interval. 
(MCMC) methods permit implementation of exact analysis of multivariate threshold models, even with large datasets.

In matrix notation, the model fitted can be written as:

$$
\lambda=\mathbf{X} \boldsymbol{\beta}+\mathbf{Z}_{\mathbf{h}} \mathbf{h}+\mathbf{Z}_{\mathbf{s}} \mathbf{s}+\mathbf{e},
$$

where

$\lambda$ is a vector of unobserved liabilities;

$\boldsymbol{\beta}$ is a vector of systematic effects;

$\mathbf{h}$ is a vector of herd-5-yr of calving effects;

$\mathbf{s}$ is a vector of sire transmitting abilities;

$\mathbf{e}$ is the vector of residual effects; and

$\mathbf{X}, \mathbf{Z}_{\mathbf{h}}$, and $\mathbf{Z}_{\mathbf{s}}$ are the corresponding incidence matrices.

The order of $\lambda$ was $\sum_{j=1}^{3} n_{j} \times 4$ where $n_{j}$ is the number of cows with records in lactation $j(j=1,2,3)$. If a cow was culled before the end of lactation, "missing liabilities" was augmented. Further, $\beta$ included month $\times$ year of calving and age of calving (first-lactation cows) or calving interval (second and third lactation) effects. Month $\times$ year of first-calving effects were in 240 classes from September 1978 through September 1998, whereas effects of month $\times$ year of second and third calving were in 229 and 217 classes, respectively. Age at first calving and calving interval had 15 and 9 levels, respectively. The order of $\mathbf{h}$ and $\mathbf{s}$ was $12 \times$ number of sires (2411) and $12 \times$ number of herd-5-yr classes $(25,033)$, respectively. Residuals were assumed to be correlated within lactation but independent between lactations, and assumed to follow the multivariate normal distribution $\mathbf{e} \sim N\left(\mathbf{0}, \mathbf{R}_{\mathbf{0}} \otimes \mathbf{I}\right)$ where

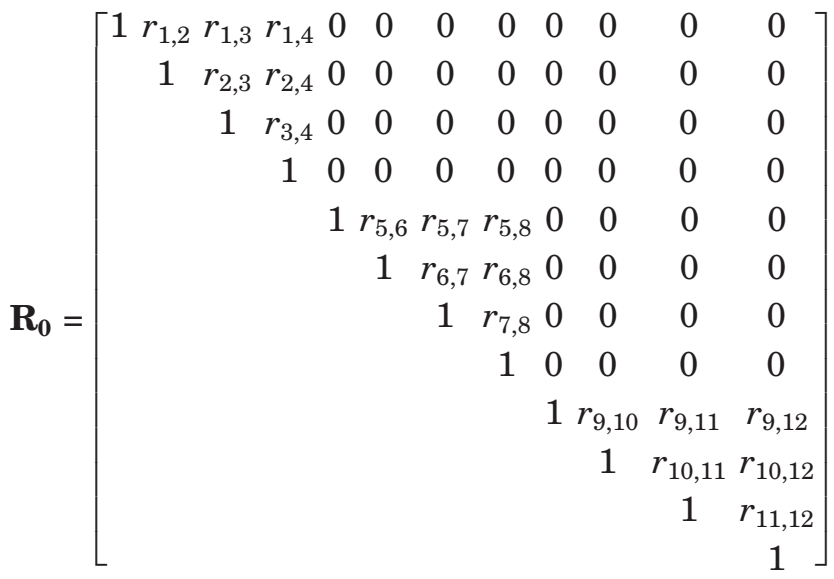

is the $12 \times 12$ residual (co)variance matrix. All residual variances were set equal to 1 .

\section{Bayesian Analysis}

A Bayesian approach employing MCMC methods in the implementation (Sorensen and Gianola, 2002), as applied by Chang et al. (2002), was used.

Prior distributions. Independent proper uniform priors were assumed for each of the elements of $\beta$ :

$$
\boldsymbol{\beta} \sim U\left(\boldsymbol{\beta}_{\min }, \boldsymbol{\beta}_{\max }\right) .
$$

Hyper-parameters values were $\boldsymbol{\beta}_{\min }=-99$ and $\boldsymbol{\beta}_{\max }=$ 99. The following multivariate normal prior distribution was assigned to the herd-5-yr effects:

$$
\mathbf{h} \sim N\left(\mathbf{0}, \mathbf{H}_{\mathbf{0}} \otimes \mathbf{I}\right),
$$

where $\mathbf{H}_{\mathbf{0}}=\left\{h_{i, j}\right\}, i, j=1,2, \ldots, 12$, is the $12 \times 12$ (co)variance matrix between herd-5-yr effects. The following multivariate normal prior distribution was assumed for the sire transmitting abilities:

$$
\mathbf{s} \sim N\left(\mathbf{0}, \mathbf{G}_{\mathbf{0}} \otimes \mathbf{A}\right),
$$

where $\mathbf{G}_{\mathbf{0}}=\left\{g_{i, j}\right\}, i, j=1,2, \ldots, 12$, is the $12 \times 12$ (co)variance matrix between sire transmitting abilities, and $\mathbf{A}$ is the matrix of additive relationships between sires. Inverse Wishart prior distributions were used for the matrices $\mathbf{H}_{\mathbf{0}}$ and $\mathbf{G}_{\mathbf{0}}$ :

$$
\begin{aligned}
& \mathbf{H}_{\mathbf{0}} \sim I W\left(\nu_{h}, \mathbf{V} h\right) \\
& \mathbf{G}_{\mathbf{0}} \sim I W\left(\nu_{g}, \mathbf{V g}\right)
\end{aligned}
$$

where $\nu_{\mathrm{h}}$ and $\nu_{\mathrm{g}}$ are the degrees of freedom parameters, and $\mathbf{V}_{\mathrm{h}}$ and $\mathbf{V}_{\mathrm{g}}$ are scale matrices. Each of the nonzero covariance elements of $\mathbf{R}_{\mathbf{0}}$ were assigned bounded uniform priors:

$$
r_{i, j} \sim U(-1,1) .
$$

Here $\mathbf{r}_{i, j}$ is the residual covariance (correlation) between interval $i$ and $j$.

The joint prior density of all unknown parameters is given by:

$$
\begin{gathered}
p\left(\boldsymbol{\beta}, \mathbf{h}, \mathbf{s}, \mathbf{R}_{\mathbf{0}}, \mathbf{H}_{\mathbf{0}}, \mathbf{G}_{\mathbf{0}} \mid \text { hyperparameters }\right) \propto \\
p(\boldsymbol{\beta}) p\left(\mathbf{h} \mid \mathbf{H}_{\mathbf{0}}\right) p\left(\mathbf{s} \mid \mathbf{G}_{\mathbf{0}}\right) p\left(\mathbf{H}_{\mathbf{0}} \mid \boldsymbol{\nu}_{h}, \mathbf{V}_{\mathbf{h}}\right) p\left(\mathbf{G}_{\mathbf{0}} \mid \nu_{g}, \mathbf{V}_{\mathbf{g}}\right)
\end{gathered}
$$

Posterior distributions. The joint posterior density of all the unknowns is proportional to the product of the joint prior density multiplied by the conditional density of the observations, given the parameters. Draws from the posterior distribution of the parameters 
were obtained using a Gibbs sampler with data augmentation (Sorensen et al., 1995). For cows that did not have data for all intervals within a lactation, "missing liabilities" were included in the augmented posterior distribution. After augmentation with the liabilities, the fully conditional distributions of all parameters, except those of the correlations in $\mathbf{R}_{\mathbf{0}}$, can be derived in closed form, as described by Sorensen et al. (1995) and Sorensen and Gianola (2002). Chang et al. (2002) give details of the Gibbs sampling scheme applied. Since the fully conditional distribution of $\mathbf{R}_{\mathbf{0}}$ does not have a closed form (because all residual variances are equal to 1), a random walk Metropolis-Hasting algorithm was used to sample the residual correlations, as described by Chang et al. (2002).

Convergence diagnostics. Convergence was assessed following Raftery and Lewis (1992) and using the first 20,000 iterations of the Gibbs chain. Using the diagnostics plus visual inspections of trace plots, it was decided to run a total chain length of 100,000 iterations after a burn-in of 10,000 iterations.

\section{Sire Evaluations and Genetic Change}

Genetic evaluations (posterior means) of sire effects were computed in the liability scale. These posterior means were transformed from the underlying liability scale to the probability ( 0 to 1 ) scale using:

$$
p_{i, j}=\Phi\left(\mu_{i}+\overline{s_{i, j}}\right)
$$

where $\mathrm{p}_{\mathrm{i}, \mathrm{j}}$ is the probability of CM in interval $i$ of an infinite number of daughters of sire $j, \Phi($.$) is the stan-$ dard normal distribution function, $\mu$ is the probit corresponding to the mean liability of CM in interval $i$, and $\overline{s_{i, j}}$ is the posterior mean of liability to $\mathrm{CM}$ in interval $i$ for sire $j$.

Genetic change was evaluated by plotting average sire posterior means against birth year of daughters, and annual genetic change was estimated from the slope of the corresponding linear regression. All daughters of the 2411 sires-i.e., a total of 1.6 million first lactation cows-were used for estimation of genetic change. Sires were weighted according to their number of daughters, so that this measure reflects sire usage as well as genetic change in the NRF population.

\section{RESULTS AND DISCUSSION}

The posterior means of heritability of liability to CM were 0.09 and 0.05 in the first and last intervals, respectively, and between 0.06 and 0.07 for other intervals
(Table 2). The posterior standard deviations ranged between 0.004 and 0.009 . For the first and third lactations, heritability was higher in the interval before calving (intervals 1 and 9). There were no differences in heritability for the second lactation intervals. The posterior distribution of heritability was sharp and symmetric, as illustrated in Figure 2, for the intervals with the highest and lowest mean (1 and 12, respectively) and the highest and lowest standard deviation (9 and 4 , respectively).

The posterior mean estimates of heritability of liability to CM agree with estimates from cross-sectional threshold model analyses of first-lactation mastitis treated as a single binary trait, which range from 0.06 to 0.12 (Lund et al., 1999; Kadarmideen et al., 2001; Heringstad et al., 2001, 2003a).

Heritability estimates were fairly similar in all three lactations (Table 2). Pösö and Mäntysaari (1996) found a lower heritability of mastitis in first lactation (0.025) than in second and third lactations (0.046 and 0.041), whereas Nielsen et al. (1997) found no evidence of differences in heritability of mastitis between lactations. However, both studies used linear models in the analysis, which makes heritability estimates frequency dependent, so the results cannot be compared directly.

Table 2 shows posterior means of the genetic correlations between liability to CM in different intervals, and the values ranged from 0.24 (intervals 1 and 12) to 0.73 (intervals 1 and 2), with posterior standard deviations between 0.03 and 0.09 . The posterior distributions of genetic correlations between selected intervals are given in Figure 3. Within lactation, genetic correlations tended to be higher for adjacent than for nonadjacent intervals, and genetic correlations between intervals in different lactations tended to be higher for intervals at the same stage of lactation (Table 2). In particular, the genetic correlations tended to be stronger for the pairs of periods $(2,6),(2,10)$, and $(6,10)$-i.e., the periods with the highest mastitis frequency within each of the lactations.

The point estimates of genetic correlations between intervals within first lactation (Table 2) were higher than the 0.13 to 0.55 range reported by Chang et al. (2001, 2002), and lower than those in Lund et al. (1999), who found genetic correlations of $0.89,0.80$, and 0.67 between clinical mastitis in early lactation ( -10 to 50 $\mathrm{d}$ after first calving) and in the periods 50 to $180 \mathrm{~d}, 180$ to $350 \mathrm{~d}$, and 50 to $350 \mathrm{~d}$ after first calving, respectively.

Estimates of genetic correlations between lactations (Table 2) were lower than the estimates of Pösö and Mäntysaari (1996) and Nielsen et al. (1997). Pösö and Mäntysaari (1996) found genetic correlations ranging from 0.67 to 0.90 between mastitis in the first 3 lactations. Nielsen et al. (1997) found correlations of 0.96, 
Table 2. Posterior means of heritability (on the diagonal) and genetic correlations (above the diagonal) for liability to clinical mastitis in 12 intervals $^{1}$ of the first 3 lactations.

\begin{tabular}{|c|c|c|c|c|c|c|c|c|c|c|c|c|}
\hline Interval $^{1}$ & 1 & 2 & 3 & 4 & 5 & 6 & 7 & 8 & 9 & 10 & 11 & 12 \\
\hline 1 & 0.09 & 0.73 & 0.41 & 0.37 & 0.55 & 0.65 & 0.38 & 0.38 & 0.53 & 0.59 & 0.28 & 0.24 \\
\hline 2 & & 0.07 & 0.50 & 0.44 & 0.51 & 0.66 & 0.49 & 0.45 & 0.52 & 0.61 & 0.42 & 0.34 \\
\hline 3 & & & 0.06 & 0.70 & 0.43 & 0.53 & 0.65 & 0.63 & 0.35 & 0.47 & 0.56 & 0.49 \\
\hline 4 & & & & 0.06 & 0.44 & 0.51 & 0.64 & 0.69 & 0.37 & 0.45 & 0.60 & 0.51 \\
\hline 5 & & & & & 0.06 & 0.56 & 0.43 & 0.44 & 0.56 & 0.50 & 0.38 & 0.31 \\
\hline 6 & & & & & & 0.06 & 0.55 & 0.51 & 0.58 & 0.68 & 0.47 & 0.38 \\
\hline 7 & & & & & & & 0.06 & 0.66 & 0.39 & 0.51 & 0.67 & 0.56 \\
\hline 8 & & & & & & & & 0.06 & 0.39 & 0.52 & 0.60 & 0.55 \\
\hline 9 & & & & & & & & & 0.07 & 0.55 & 0.37 & 0.31 \\
\hline 10 & & & & & & & & & & 0.06 & 0.48 & 0.37 \\
\hline 11 & & & & & & & & & & & 0.06 & 0.55 \\
\hline 12 & & & & & & & & & & & & 0.05 \\
\hline
\end{tabular}

${ }^{1}$ Each lactation was divided into 4 intervals: $(-30,0),(1,30),(31,120)$, and $(121,300)$ days after calving. Intervals 1 to 4 are first lactation, intervals 5 to 8 are second lactation, and intervals 9 to 12 are third lactation.

0.95 , and 0.76 between first and second lactation, for Red Danish, Danish Friesian, and Danish Jersey, respectively; between first and third lactations, the estimates were $0.92,0.86$, and 0.65 , and between second and third lactations, the correlations were $1.0,0.98$, and 0.99 for the 3 breeds.

Posterior means of residual correlations ranged from 0.08 to 0.17 for adjacent intervals, and between -0.01 and 0.03 for nonadjacent intervals (Table 3 ). The posterior distributions of the residual correlations between the 4 intervals of first lactation are shown in Figure 4. The corresponding distributions for second and third lactations were similar. For many nonadjacent inter-

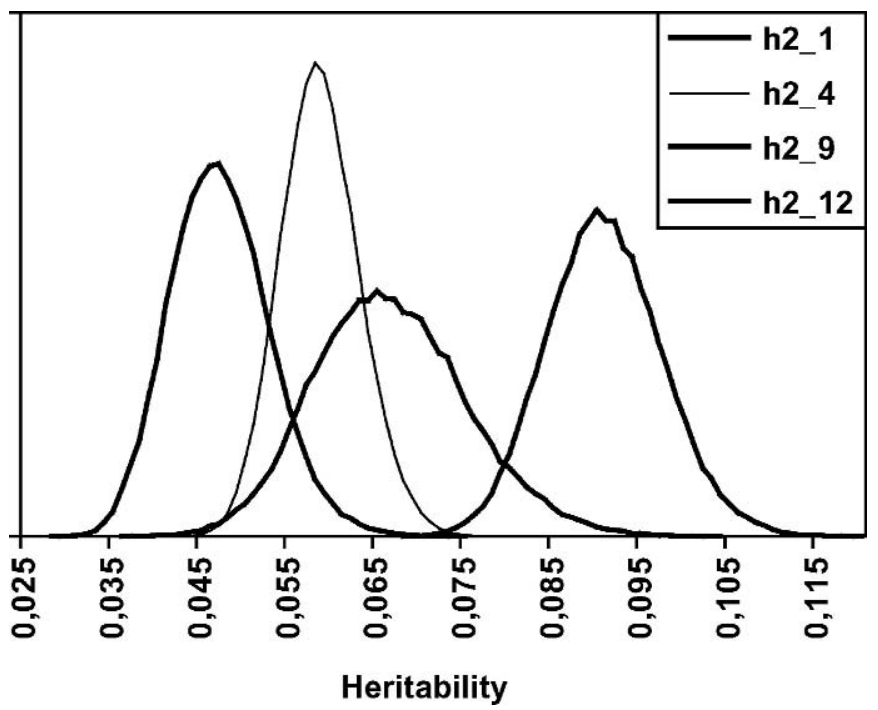

Figure 2. Posterior distributions of heritability $\left(\mathrm{h}^{2} \_i=4 \sigma_{\mathrm{s}}^{2}\right)$ $\left.\left(\sigma^{2}+\sigma^{2}{ }_{h}+1\right)\right)$ of liability to clinical mastitis for selected intervals $i$. The posterior distributions with the highest mean $\left(h^{2}{ }^{2} 1\right)$, the lowest mean $\left(\mathrm{h}^{2} \_12\right)$, the highest $\mathrm{SD}\left(\mathrm{h}^{2}-9\right)$, and lowest $\mathrm{SD}\left(\mathrm{h}^{2}{ }_{4}\right)$ are shown. From left to right the distributions are $\mathrm{h}^{2}{ }_{-} 12, \mathrm{~h}^{2}{ }_{-} 4, \mathrm{~h}^{2} \_9$, and $\mathrm{h}^{2}{ }_{-} 1$. vals, the distribution includes zero. Our results suggest that residuals between nonadjacent intervals can be assumed to be uncorrelated, whereas residuals between adjacent intervals should be regarded as having a dependency structure. Here, zero residual correlations between lactations were assumed. However, other structures of the residual (co)variance matrix could be examined.

The between herd-5-yr variance was 0.18 in interval 1 and varied between 0.09 and 0.14 subsequently (Table 3 ), with posterior standard deviations between 0.003 and 0.008. This is in agreement with results of Chang et al. (2001, 2002) and Heringstad et al. (2003a). However, the estimates were somewhat higher than the between herd-5-yr variance found with a longitudinal threshold model analysis (Heringstad et al., 2003b),

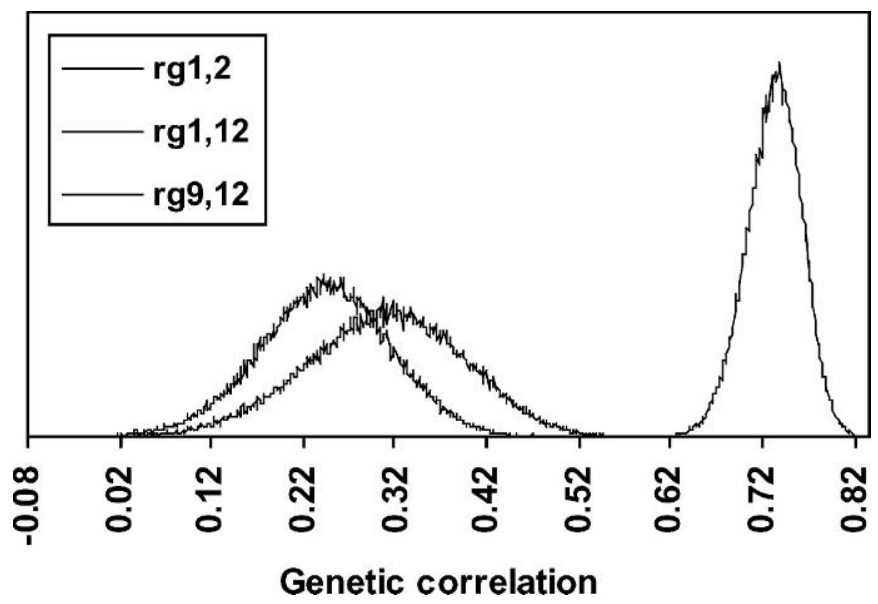

Figure 3. Posterior distributions of genetic correlations $\left(\mathrm{g}_{i, j}\right)$ between liability to clinical mastitis in selected lactation intervals $i$ and $\mathrm{j}$. The posterior distributions with the highest mean $\left(\mathrm{r}_{\mathrm{g} 1,2}\right)$, the lowest mean $\left(\mathrm{r}_{\mathrm{g} 1,12}\right)$, the highest $\mathrm{SD}\left(\mathrm{r}_{\mathrm{g} 9,12}\right)$, and lowest $\mathrm{SD}\left(\mathrm{r}_{\mathrm{g} 1,2}\right)$ are shown. From left to right the distributions are $r_{\mathrm{g} 1,12}, r_{\mathrm{g} 9,12}$, and $\mathrm{r}_{\mathrm{g} 1,2}$. 
Table 3. Posterior means of herd-5-year variance (on the diagonal), herd-5-year correlations (above the diagonal), and residual correlations (below the diagonal) for liability to clinical mastitis in 12 intervals ${ }^{1}$ of the first 3 lactations.

\begin{tabular}{|c|c|c|c|c|c|c|c|c|c|c|c|c|}
\hline Interval $^{1}$ & 1 & 2 & 3 & 4 & 5 & 6 & 7 & 8 & 9 & 10 & 11 & 12 \\
\hline 1 & 0.18 & 0.73 & 0.47 & 0.49 & 0.78 & 0.63 & 0.41 & 0.45 & 0.69 & 0.53 & 0.40 & 0.41 \\
\hline 2 & 0.13 & 0.12 & 0.68 & 0.64 & 0.65 & 0.83 & 0.63 & 0.59 & 0.59 & 0.75 & 0.58 & 0.56 \\
\hline 3 & 0.03 & 0.12 & 0.09 & 0.79 & 0.47 & 0.72 & 0.82 & 0.76 & 0.45 & 0.69 & 0.75 & 0.70 \\
\hline 4 & -0.01 & 0.02 & 0.17 & 0.11 & 0.56 & 0.73 & 0.84 & 0.86 & 0.57 & 0.73 & 0.78 & 0.79 \\
\hline 5 & & & & & 0.14 & 0.63 & 0.47 & 0.51 & 0.81 & 0.59 & 0.44 & 0.45 \\
\hline 6 & & & & & 0.10 & 0.11 & 0.73 & 0.69 & 0.64 & 0.84 & 0.68 & 0.65 \\
\hline 7 & & & & & 0.00 & 0.15 & 0.10 & 0.84 & 0.49 & 0.76 & 0.84 & 0.78 \\
\hline 8 & & & & & 0.00 & 0.03 & 0.16 & 0.12 & 0.55 & 0.74 & 0.84 & 0.85 \\
\hline 9 & & & & & & & & & 0.12 & 0.61 & 0.46 & 0.50 \\
\hline 10 & & & & & & & & & 0.08 & 0.11 & 0.73 & 0.72 \\
\hline 11 & & & & & & & & & 0.004 & 0.12 & 0.10 & 0.81 \\
\hline 12 & & & & & & & & & 0.01 & 0.02 & 0.16 & 0.13 \\
\hline
\end{tabular}

${ }^{1}$ Each lactation was divided into 4 intervals: $(-30,0),(1,30),(31,120)$, and $(121,300)$ days after calving. Intervals 1 to 4 are first lactation, intervals 5 to 8 are second lactation, and intervals 9 to 12 are third lactation.

where the posterior means (SD) was 0.065 (0.004). Correlations between herd-5-yr effects between intervals were positive and high (Table 3 ). Posterior means varied between 0.40 and 0.86 , with posterior standard deviations between 0.013 and 0.034 . Higher herd correlations were observed between intervals at the same stage of lactation than between intervals within the same lactation.

Rank correlations between posterior means of sire transmitting abilities in the 12 intervals ranged from 0.48 to 0.91 (Table 4). Within lactation, rank correlations were higher between adjacent than between nonadjacent intervals. Rank correlations between intervals in different lactations tended to be higher for intervals at the same stage of lactation. Table 5 shows how the top 10 sires from interval 2 ranked for the other 11 intervals. For some sires (e.g., the sire ranked second in interval 2), there was reasonably good agreement

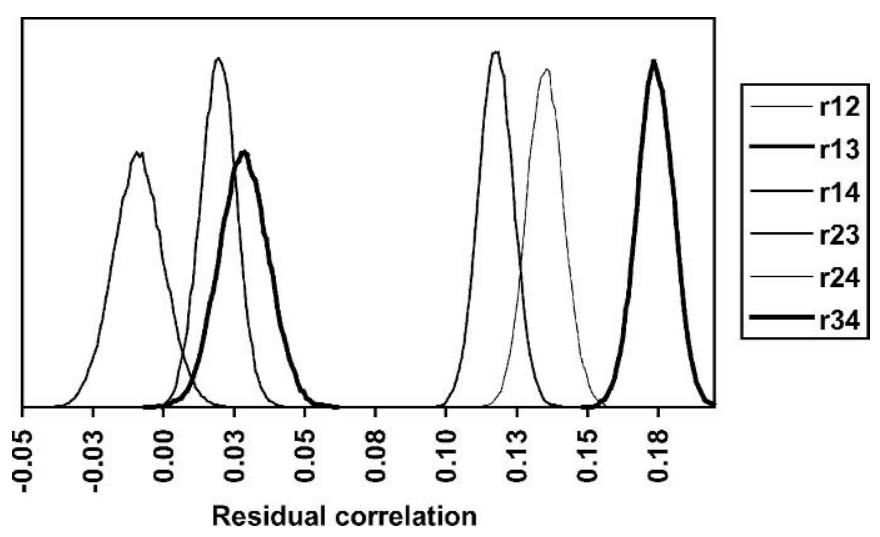

Figure 4. Posterior distributions of residual correlations $\left(\mathrm{r}_{i, j}\right)$ between the 4 intervals of first lactation. From left to right the distributions are $\mathbf{r}_{14}, \mathrm{r}_{24}, \mathrm{r}_{13}, \mathrm{r}_{23}, \mathrm{r}_{12}$, and $\mathrm{r}_{34}$. between rankings in different intervals. On the other hand, the sire ranked as third in interval 2 was ranked as number 5 in the first interval, but took between the 129 and 1095 positions in the remaining 10 intervals. This illustrates that selection of sires depends on the number of intervals and lactations included in genetic evaluation.

Mean sire posterior means by birth year of daughters for each interval are given in Figure 5. All trends are presented as deviations from the average of the sire posterior means of sires of cows born in 1976. For intervals in early lactation, the curves were relatively flat in the beginning, suggesting little or no genetic change, and decreasing toward the end of the time period. This trajectory is in agreement with Heringstad et al. (2003a), who found genetic improvement for mastitis resistance in first lactation for NRF in recent years. For intervals later in lactation, curves were increasing in the beginning and decreasing toward the end of the time period (Figure 5).

There was genetic improvement for all 12 traits after 1985 (Figure 5). For example, the average transmitting ability for CM in interval 2 ( 1 to $30 \mathrm{~d}$ after first calving) of sires of cows born in 1996 was $1.2 \%$ points lower than for sires of cows born in 1986.

Annual genetic changes for the 12 traits are given in Table 6. For the total time period (cows born from 1976 to 1996), annual genetic change varied between -0.065 (interval 2) and 0.012 (interval 8) \%-points CM. For cows born after 1985, the annual genetic change for the 12 traits was estimated to be between -0.04 and $-0.14 \%$-points CM (Table 6). Annual genetic change was largest (in absolute value) in intervals 2,6 , and 10 , and smallest in intervals 5 and 9 . In an univariate threshold model analysis of mastitis in first lactation ( -15 to $120 \mathrm{~d}$ after first calving), Heringstad et al. 
Table 4. Rank correlations between sire posterior means for liability to clinical mastitis in 12 intervals ${ }^{1}$ of the first 3 lactations.

\begin{tabular}{|c|c|c|c|c|c|c|c|c|c|c|c|}
\hline Interval & 2 & 3 & 4 & 5 & 6 & 7 & 8 & 9 & 10 & 11 & 12 \\
\hline 1 & 0.91 & 0.58 & 0.52 & 0.79 & 0.85 & 0.57 & 0.56 & 0.78 & 0.80 & 0.48 & 0.48 \\
\hline 2 & & 0.69 & 0.62 & 0.77 & 0.85 & 0.69 & 0.64 & 0.76 & 0.82 & 0.61 & 0.58 \\
\hline 3 & & & 0.91 & 0.67 & 0.72 & 0.87 & 0.87 & 0.56 & 0.69 & 0.80 & 0.77 \\
\hline 4 & & & & 0.65 & 0.67 & 0.86 & 0.91 & 0.55 & 0.66 & 0.82 & 0.79 \\
\hline 5 & & & & & 0.83 & 0.66 & 0.65 & 0.85 & 0.81 & 0.64 & 0.57 \\
\hline 6 & & & & & & 0.74 & 0.70 & 0.84 & 0.91 & 0.68 & 0.62 \\
\hline 7 & & & & & & & 0.88 & 0.61 & 0.74 & 0.89 & 0.82 \\
\hline 8 & & & & & & & & 0.59 & 0.70 & 0.83 & 0.83 \\
\hline 9 & & & & & & & & & 0.82 & 0.59 & 0.56 \\
\hline 10 & & & & & & & & & & 0.71 & 0.62 \\
\hline 11 & & & & & & & & & & & 0.82 \\
\hline
\end{tabular}

${ }^{1}$ Each lactation was divided into 4 intervals: $(-30,0),(1,30),(31,120)$, and $(121,300)$ days after calving. Intervals 1 to 4 are first lactation, intervals 5 to 8 are second lactation, and intervals 9 to 12 are third lactation.

(2003a) found an annual genetic change of $-0.08 \%$ points CM for cows born from 1976 to 1990 , and $-0.27 \%$ points CM for cows born after 1989. In the present study, lactations were divided into 4 intervals, so genetic change in each interval was expected to be smaller than in Heringstad et al. (2003a).

Trends were steeper in first than in second and third lactations. Also, in all 3 lactations, the trend was steeper for intervals in early lactation than for later intervals (Figure 5 and Table 6). These results are not surprising, given the genetic correlations in Table 2 and the fact that selection against mastitis in NRF has focused on mastitis in the period from $15 \mathrm{~d}$ before to $120 \mathrm{~d}$ after first calving. Intervals 1 and 2 , and intervals with large genetic correlations with intervals 1 and 2 show the steepest trends. It appears that effective selection against CM in early first lactation gave a favorable indirect selection response in other intervals; this is consistent with the positive genetic correlations between intervals (Table 2).

As opposed to cross-sectional analyses, where CM is treated as a single binary trait, the multivariate mod- els, with lactations divided into intervals, take both multiple CM episodes and time aspects into account. Also, a possible sampling bias due to culling of cows can be reduced in such models as "incomplete lactations," and records in progress can be included in the analyses.

Here we chose to divide lactations into 4 intervals, with shorter intervals around calving and longer intervals later in lactation. This was based on Chang (2002), who found that models with 4 and 11 intervals had good agreement with respect to sire ranking. Longer and fewer intervals may obscure variation between animals, whereas shorter and more intervals require more computational time, since this leads to more records per animal and to a more highly parameterized model.

\section{CONCLUSIONS}

Genetic improvement of mastitis resistance is being achieved in NRF. Our results suggest that effective selection against CM in early first lactation has elicited

Table 5. The top 10 sires from interval 2 ( 1 to $30 \mathrm{~d}$ after first calving) and their rank for the other 11 intervals ${ }^{1}$.

\begin{tabular}{|c|c|c|c|c|c|c|c|c|c|c|c|}
\hline \multicolumn{12}{|c|}{ Sire ranking in interval ${ }^{1}$} \\
\hline 1 & 2 & 3 & 4 & 5 & 6 & 7 & 8 & 9 & 10 & 11 & 12 \\
\hline 2 & 1 & 76 & 23 & 194 & 17 & 60 & 41 & 57 & 46 & 94 & 112 \\
\hline 1 & 2 & 13 & 18 & 7 & 1 & 2 & 29 & 4 & 2 & 24 & 82 \\
\hline 5 & 3 & 412 & 460 & 687 & 129 & 776 & 435 & 169 & 517 & 1095 & 923 \\
\hline 22 & 4 & 132 & 207 & 160 & 56 & 487 & 467 & 293 & 192 & 421 & 351 \\
\hline 30 & 5 & 51 & 39 & 217 & 20 & 69 & 132 & 146 & 35 & 34 & 311 \\
\hline 24 & 6 & 10 & 10 & 67 & 6 & 35 & 10 & 31 & 6 & 1 & 29 \\
\hline 61 & 7 & 324 & 500 & 571 & 189 & 451 & 404 & 271 & 329 & 667 & 598 \\
\hline 6 & 8 & 14 & 50 & 9 & 8 & 80 & 90 & 39 & 4 & 52 & 124 \\
\hline 4 & 9 & 187 & 544 & 345 & 101 & 447 & 311 & 89 & 142 & 730 & 662 \\
\hline 80 & 10 & 38 & 79 & 305 & 64 & 169 & 104 & 219 & 199 & 276 & 191 \\
\hline
\end{tabular}

${ }^{1}$ Each lactation was divided into 4 intervals: $(-30,0),(1,30),(31,120)$, and $(121,300)$ days after calving. Interval 1 to 4 is first lactation, intervals 5 to 8 are second lactation, and intervals 9 to 12 are third lactation. 

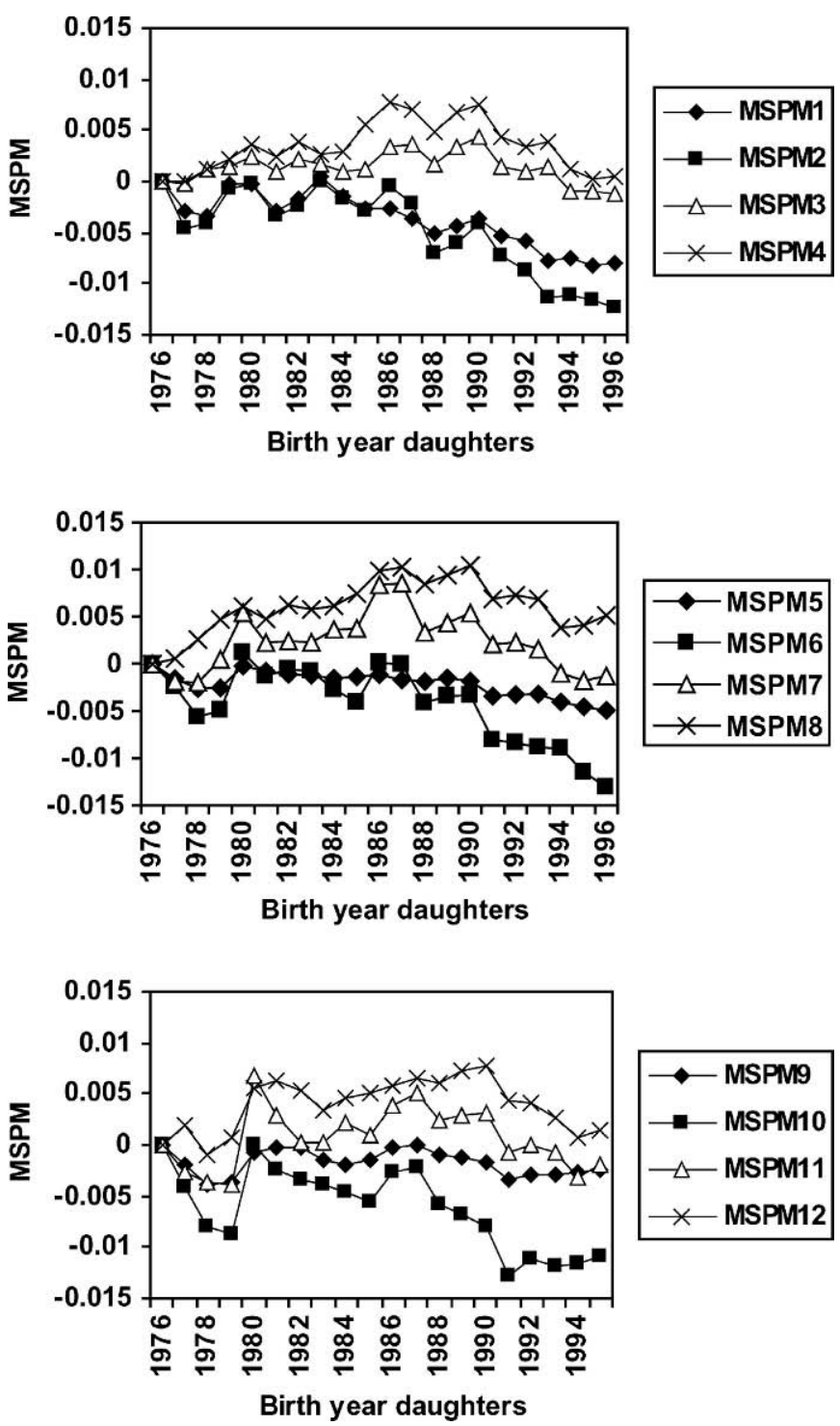

Figure 5. Mean sire posterior means (MSPM) in the probability scale, given as deviation from MSPM for cows born in 1976, by birth year of daughters for the 12 intervals.

favorable correlated selection responses in other intervals in first, second, and third lactations.

Genetic correlations much lower than 1 indicate that mastitis cannot be regarded as the same trait in different parts of lactation or in different lactations. This implies that a multivariate threshold model treating mastitis in different stages of lactation as different traits may be required for genetic evaluation.

\section{ACKNOWLEDGMENTS}

Access to the data was given by the Norwegian Dairy Herd Recording System and by the Norwegian Cattle
Table 6. Linear regressions of sire posterior mean in the probability scale on birth year of daughters for all cows (1976 to 1996) and for cows born after 1985 .

\begin{tabular}{lccc}
\hline \multirow{2}{*}{ Lactation } & & \multicolumn{2}{c}{ Regression coefficient $(\times 100)^{1}$} \\
\cline { 3 - 4 } & & All cows & $\begin{array}{c}\text { Cows born } \\
\text { after 1985 }\end{array}$ \\
\hline 1 & 1 & -0.043 & -0.057 \\
& 2 & -0.065 & -0.115 \\
& 3 & -0.008 & -0.051 \\
2 & 4 & -0.001 & -0.077 \\
& 5 & -0.019 & -0.037 \\
& 6 & -0.056 & -0.127 \\
3 & 7 & -0.008 & -0.106 \\
& 8 & 0.012 & -0.069 \\
& 9 & -0.010 & -0.040 \\
& 10 & -0.060 & -0.140 \\
& 11 & -0.007 & -0.087 \\
& 12 & 0.003 & -0.062 \\
\hline
\end{tabular}

${ }^{1}$ Regression coefficient $(\times 100)$ gives annual genetic change in \%points mastitis.

Health Service in agreement number 011.2000 by 12.10.2000. GENO Breeding and A. I. Association is acknowledged for providing pedigree information on sires. This work is part of the "Healthy Cow" project financed by the Research Council of Norway. Support has also been received from the Babcock Institute for International Dairy Research and Development, University of Wisconsin-Madison, by NFS grant DEB00.89742 and by grant NRICGP/USDA 99-35205-8162.

\section{REFERENCES}

Chang, Y. M., R. Rekaya, D. Gianola, B. Heringstad, and G. Klemetsdal. 2001. Correlations between clinical mastitis at different stages of lactation in Norwegian Cattle using a multivariate threshold model. J. Dairy Sci. 84(Suppl. 1):110. (Abstr.)

Chang, Y. M., D. Gianola, B. Heringstad, and G. Klemetsdal. 2002. Correlations between clinical mastitis in different periods of first lactation Norwegian Cattle using a multivariate threshold model. Pages 177-192 in Case Studies in Bayesian Statistics, Vol. 6. C. Gatsonis, A. Carriquiry, A. Gelman, D. Higdon, R. Kass, D. Pauler, and I. Verdinelli, ed. Springer Verlag, New York, NY.

Chang, Y. M. 2002. Multivariate and longitudinal models for binary data with applications to clinical mastitis in Norwegian cattle. Ph.D. Diss. University of Wisconsin, Madison.

Foulley, J. L., and D. Gianola. 1984. Estimation of genetic merit from bivariate "all-or-none" responses. Genet. Sel. Evol. 16:285-306.

Foulley, J. L., and D. Gianola. 1986. Sire evaluation for multiple binary responses when information is missing on some traits. J. Dairy Sci. 69:2681-2695.

Foulley, J. L., S. Im, D. Gianola, and I. Hoeschele. 1987. Empirical Bayes estimation of genetic value for $\mathrm{n}$ binary traits. Genet. Sel. Evol. 19:197-224.

Gianola, D., and J. L. Foulley. 1983. Sire evaluation for ordered categorical data with a threshold model. Genet. Sel. Evol. 15:201-223.

Heringstad B., G. Klemetsdal, and J. Ruane. 2000. Selection for mastitis resistance in dairy cattle-A review with focus on the situation in the Nordic countries. Livest. Prod. Sci. 64:95-106.

Heringstad, B., R. Rekaya, D. Gianola, G. Klemetsdal, and K. A. Weigel. 2001. Bayesian analysis of liability to clinical mastitis in Norwegian Cattle with a threshold model: Effects of data sampling method and model specification. J. Dairy Sci. 84:2337-2346. 
Heringstad, B., R. Rekaya, D. Gianola, G. Klemetsdal, and K. A. Weigel. 2003a. Genetic change for clinical mastitis in Norwegian Cattle: A threshold model analysis. J. Dairy Sci. 86:369-375.

Heringstad, B., Y. M. Chang, D. Gianola, and G. Klemetsdal. 2003b. Genetic analysis of longitudinal trajectory of clinical mastitis in first-lactation Norwegian Cattle. J. Dairy Sci. 86:2676-2683.

Hoeschele, I., J. L. Foulley, J. J. Colleau, and D. Gianola. 1986. Genetic evaluation for multiple binary responses. Genet. Sel. Evol. 18:299-320.

Kadarmideen, H. N., R. Rekaya, and D. Gianola. 2001. Genetic parameters for clinical mastitis in Holstein-Friesians in the United Kingdom: A Bayesian analysis. Anim. Sci. 73:229-240.

Lund, M. S., J. Jensen, and P. H. Petersen. 1999. Estimation of genetic and phenotypic parameters for clinical mastitis, somatic cell production deviance, and protein yield in dairy cattle using Gibbs sampling. J. Dairy Sci. 82:1045-1051.
Nielsen, U. S., G. A. Pedersen, and J. Jensen. 1997. Genetic correlations among health traits in different lactations. Interbull Bull. 15:68-77.

Pösö, J., and E. A. Mäntysaari. 1996. Relationships between clinical mastitis, somatic cell score, and production in the first three lactations of Finnish Ayrshire. J. Dairy Sci. 79:1284-1291.

Raftery, A. L., and S. Lewis. 1992. How many iterations in the Gibbs sampler? Pages 763-774 in Bayesian Statistics 4. J. M. Bernando, J. O. Berger, A. P. Dawid, and A. F. M. Smith, ed. Oxford University Press, Oxford, UK.

Sorensen, D. A., S. Andersen, D. Gianola, and I. Korsgaard. 1995. Bayesian inference in threshold models using Gibbs sampling. Genet. Sel. Evol. 27:229-249.

Sorensen, D., and D. Gianola. 2002. Likelihood, Bayesian, and MCMC methods in quantitative genetics. Springer-Verlag, New York, NY. 